\title{
Classic EKG Changes of Hypothermia
}

\author{
Ravi K. Mareedu, MD; Naga P. Grandhe, MD; Srinivas Gangineni, MD; and Daniel L Quinn, MD
}

A

51-year-old female was found lying in a wet damp area near a rural Wisconsin roadside in early spring. The patient was unresponsive and multiple empty medication bottles were found near her body. At the time of admission to the emergency department, her temperature was $80.4^{\circ} \mathrm{F}\left(26.8^{\circ} \mathrm{C}\right)$ with her blood pressure at $80 / 50 \mathrm{~mm} \mathrm{Hg}$. She was intubated for airway protection. The empty medication bottles found included prescriptions for citalopram, aripiprazole, ziprasidone, trazodone, clonazepam, oxycodone, levothyroxine and lansoprazole. She had multiple electrolyte abnormalities (potassium $2.5 \mathrm{mmol} / \mathrm{L}$, magnesium $1.6 \mathrm{mg} / \mathrm{dL}$, phosphate $1.3 \mathrm{mg} / \mathrm{dL}$, and ionized calcium $4.2 \mathrm{mg} / \mathrm{dL}$ ).

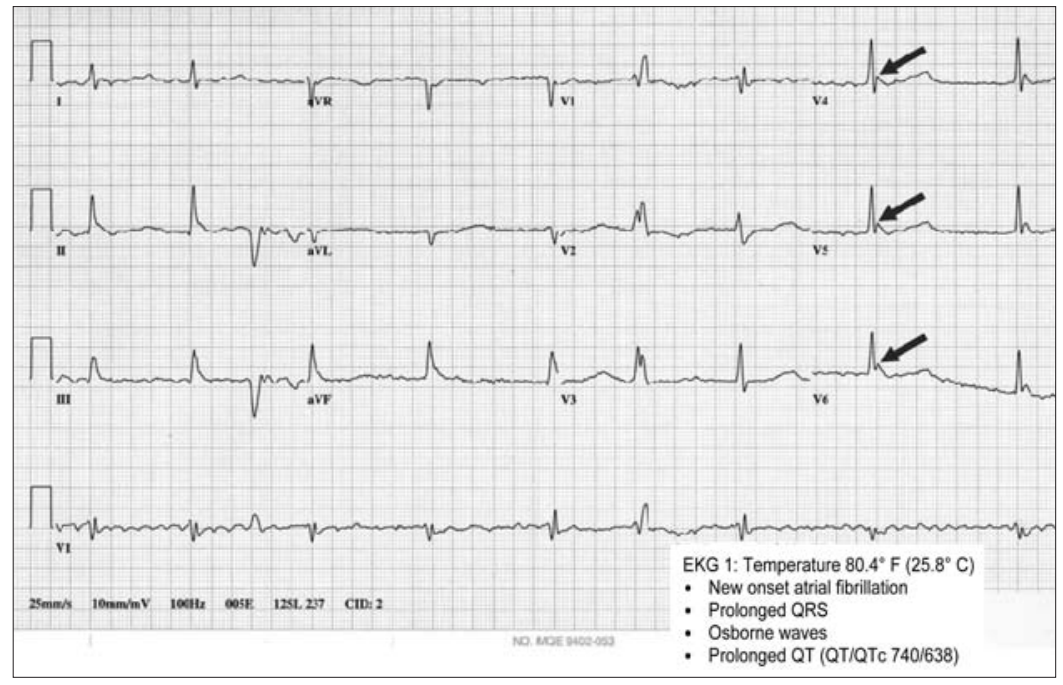

Figure 1. Initial EKG with classic findings of hypoxia at body temperature of $80.4^{\circ} \mathrm{F}$.
Her EKG (figure 1) showed evidence of hypothermia with prolonged QRS and Osborne waves (arrows in figure 1), new onset atrial fibrillation, and prolonged QT (QT/QTc 740/688). Members of the emergency department staff were able to rewarm her using warm saline, radiant heat, and warm air (Bair hugger). Her body temperature slowly increased to $88.3^{\circ} \mathrm{F}$ $\left(31.3^{\circ} \mathrm{C}\right)$ within the next 4 hours with significant reversal of her EKG changes (figure 2), including reverting back to sinus rhythm, normalization of QRS waves (88 milliseconds) with resolution of Osborne waves and improvement in QT (QT/QTc 504/577). By 12 hours post-admission, her temperature was raised to $99^{\circ} \mathrm{F}\left(37.2^{\circ} \mathrm{C}\right)$.

The patient's cardiac enzymes remained negative. Her comprehensive urine drug screen was positive for oxycodone, oxymorphone, trazodone,

\section{Author Affiliations:}

*†Ravi K. Mareedu, MD; Naga P. Grandhe, MD; and

Srinivas Gangineni, MD; Department of Internal Medicine,

Marshfield Clinic, Marshfield, Wisconsin

Daniel L. Quinn, MD; Department of Pulmonary Medicine,

Marshfield Clinic, Marshfield, Wisconsin

* Corresponding Author

† Present Address: Cardiology Fellow

Division of Cardiovascular Medicine

9200 West Wisconsin Avenue STE 5100

Milwaukee, WI 53226

Tel: 4|4-456-6993

Email: rmareedu@mcw.edu
Keywords: EKG changes; Hypothermia; J waves; Osborne waves

Received: June 19, 2008

Revised: August 12, 2008

Accepted: August 27, 2008

doi: $10.3121 / \mathrm{cmr} .2008 .809$

The Aperture, like the opening in the lens of a microscope that allows light to pass through, is a forum for art, humor, and images that provides a portal for new or different views of medicine and research. 


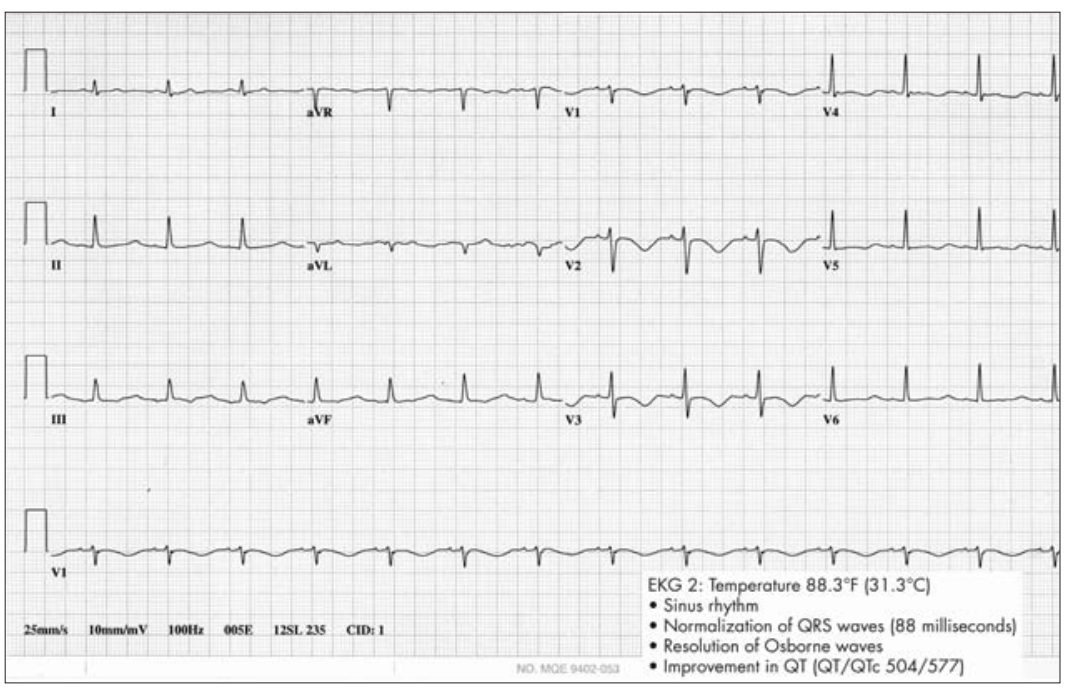

Figure 2. Repeat EKG in next 4 hours with significant reversal of her EKG changes at body temperature of $88.3^{\circ} \mathrm{F}$.

lidocaine, and citalopram. She was extubated in less than 24 hours and was discharged from hospital in 3 days. The incident was thought to be an attempted suicide, which resulted in her exposure to cold weather conditions for 24 hours.

$\mathrm{J}$ waves (also called Osborne waves) are pathognomonic for hypothermia when present. ${ }^{1}$ These look like "delta" or "camel's hump" waves after regular QRS complex. ${ }^{1} \mathrm{~J}$ waves or Osborne waves appear secondary to an exaggerated outward potassium current leading to repolarization abnormality. ${ }^{2}$ These waves are detectable in $80 \%$ of the patients when core body temperature is lower than $30^{\circ} \mathrm{C} .^{3}$ $\mathrm{J}$ waves are seen in lead II and precordial leads V2-V6. ${ }^{1}$ Similar findings can be seen in patients with hypercalcemia, Brugada syndrome, and early repolarization. ${ }^{1}$ Our patient had significant hypokalemia and it could have contributed to the prolonged QRS. It should be noted, however, that the plasma potassium levels do not generally correspond to the electrocardiographic changes of hypokalemia. ${ }^{4} \mathrm{~J}$ waves are not prognostic indicators when they are present, unlike atrial fibrillation, which incurs survival disadvantage. ${ }^{5}$ Fatal ventricular fibrillation or asystole can occur when core body temperature is below $28^{\circ} \mathrm{C} .{ }^{1}$

\section{References}

1. Alsafwah S. Electrocardiographic changes in hypothermia. Heart Lung 2001;30:161-163.

2. Olgers TJ, Ubels FL. The ECG in hypothermia: Osborn waves. Neth J Med 2006;64:350, 353

3. Nolan J, Soar J. Images in resuscitation: the ECG in hypothermia. Resuscitation 2005;64:133-134.

4. Fauci AS, Braunwald E, Kasper DL, Hauser SL, Longo DL, Jameson JL, Loscalzo J, eds. Harrison's principles of internal medicine. 17th ed. New York, NY: McGraw-Hill; 2008.

5. Graham CA, McNaughton GW, Wyatt JP. The electrocardiogram in hypothermia. Wilderness Environ Med 2001;12:232-235.

\section{Figure Attributions: Systemic Blastomycosis Diagnosed by Prostate Needle Biopsy (Clin Med Res 2008; 6:24-28. doi: | 0.3 I 2 I/cmr.2008.789)}

\author{
Peter M. Neal, $\mathrm{MD}^{\dagger}$ and Anne Nikolai, BS
}

${ }^{\dagger}$ Address correspondence to: Peter M. Neal, MD; Marshfield Clinic Indianhead Center, Department of Urology; 1020 Lakeshore Drive; Rice Lake, WI 54868; Tel: 7I5-236-83I3; Fax: 7I5-236-8I04; Email: neal.peter@marshfieldclinic.org.

Editor's note: The article to which this erratum refers was published in the May 2008 issue of Clinical Medicine \& Research (Clin Med Res 2008; 6:24-28. doi: $\mid 0.3121 /$ cmr.2008.789).

he authors inadvertently omitted the attributions for several figures in their recent article. Figures 2, 3 and 4, and their descriptions, were contributed by Kathryn A. Kolquist, MD, Marshfield Laboratories-Pathology, Marshfield, Wisconsin. The authors sincerely apologize to Dr. Kolquist for this omission.

Keywords: Blastomycosis; Prostatic diagnosis; Mycotic disease

Received: October 30, 2008

doi: $10.3|2| / \mathrm{cmr} \cdot 2008.789 . c o r r$ 